\title{
Effect of thermal treatment on points defects of Al-N codoped ZnO films
}

\author{
Luis Zamora Peredo ${ }^{1}$, Isaac Martínez Velis ${ }^{1}$, Antonio Martínez ${ }^{1}$,Julián Hernández Torres ${ }^{1}$, \\ Leandro García González ${ }^{1}$, Lada Domratcheva Lvova², Nelly Flores Ramírez², \\ Salomón Vásquez García ${ }^{2}$, Guillermo Santana Rodríguez ${ }^{3}$
}

\footnotetext{
${ }^{1}$ Centro de Investigación en Micro y Nanotecnología, Universidad Veracruzana, A. Ruiz Cortines 455, C.P. 91000, Veracruz, México

e-mail: luiszamora@uv.mx; sissa85@gmail.com; antonio_mj92@hotmail.com; julihernandez@uv.mx; leagarcia@uv.mx

${ }^{2}$ Universidad Michoacana de San Nicolás de Hidalgo Gral. Francisco J. Múgica S/N, Felicitas del Río, C. P. 58030, Morelia, Michoacán, México.

e-mail: ladamex@yahoo.es; fr_nelly@yahoo.com; salomon_vg@yahoo.com

${ }^{3}$ Instituto de Investigaciones en Materiales, Universidad Nacional Autónoma de México, Coyoacán, México DF, C.P. 04510, Coyoacán, Ciudad de México, Mexico.

e-mail: gsantana@iim.unam.mx
}

\section{ABSTRACT}

The effect of annealing temperature on the structural properties of Al-N codoped $\mathrm{ZnO}$ films were studied by $\mathrm{X}$-ray diffraction, photoluminescence and Raman spectroscopy. ZnO films were deposited by sputtering technique on silicon substrates at $20^{\circ} \mathrm{C}$, Al-concentration was kept constant and $\mathrm{N}$-flow was changed to 6,12 and $15 \mathrm{sccm}$. A thermal treatment was performed by annealing the sample during 30 minutes at 300, 400, 500, 600 and $700{ }^{\circ} \mathrm{C}$. Before annealing, Raman spectra shows two vibration modes located at 275 and 580 $\mathrm{cm}-1$ associated to the nitrogen incorporation and the presence of point defects. Both Raman intensities of modes I275 and I580 decreases when the nitrogen flow increases from 6 to 12 and $15 \mathrm{sccm}$, which is originated by a decreasing interstitial defects density. The improving of the crystal quality was confirmed by $\mathrm{X}$-ray diffraction and room temperature photoluminescence measurements. After annealing, in the Raman spectra it was observed that $\mathrm{I} 275$ increases as the temperature increase, reaches a maximum intensity between 500 and $600{ }^{\circ} \mathrm{C}$, and decreases for higher temperatures. X-ray diffraction measurements show that after annealing the compressive stress decrease progressively as the annealing temperature increase. This study suggests that 275 Raman mode could be used to estimate the optimal thermal treatment in order to achieve pdoping $\mathrm{ZnO}$.

Keywords: Zinc oxide, codoping, annealing, Raman spectroscopy, XRD.

\section{INTRODUCTION}

Zinc oxide $(\mathrm{ZnO})$ is a semiconductor with special interest because it has a wide band gap (3.36 eV at $300 \mathrm{~K})$ and large exciton binding energy $(60 \mathrm{meV})$, which can be widely used in the manufacture of optoelectronic devices such light-emitting diodes, laser diodes, photo-detectors, transparent electrodes, gas sensors and solar cells. One of the big challenges is to control the p-type doping due to its high activation energy and the low solubility of acceptor dopants. Another feature of $\mathrm{ZnO}$ not favorable to the p-type doping is the presence of native defects such as interstitial and vacancies acting as an n-type doping, generating a phenomenon known as self-compensation [1-3]. Nitrogen is the doping elements frequently used in order to replace the oxygen atoms and consequently increases the hole concentration. However, another factor limiting the production of high levels of p-type doping is the low solubility of nitrogen originated by a weak bond N-Zn, which is easily broken at high growth temperatures $\left(300-600{ }^{\circ} \mathrm{C}\right)$. Codoping is an alternative method that has been proposed, using acceptors and reactive donors simultaneously in order to achieve p-type $\mathrm{ZnO}$ [4]. In several studies were used elements such as P [5, 6], In [7,8], Be [9], Ag [10] and Al [11-19] in addition to nitrogen atoms, in order to increase incorporation of $\mathrm{N}$ into the $\mathrm{ZnO}$ crystalline lattice. Other important factors that help to p-doping are the growth temperature and the post-annealing process. Chen et al. [8] studied In-N codoped $\mathrm{ZnO}$ films grown on different substrates and they found that $540{ }^{\circ} \mathrm{C}$ is the optimal temperature; may be, this is the explanation why Zeng et al. [11] got p-conductivity in Al-N codoped $\mathrm{ZnO}$ films sputtered at 
$500{ }^{\circ} \mathrm{C}$ and Shinho et al. [12] observed n-conductivity in Al-N codoped $\mathrm{ZnO}$ sputtered at $300{ }^{\circ} \mathrm{C}$. Other studies used thermal annealing in order to ensure the nitrogen incorporation in oxygen sites $\left(\mathrm{N}_{\mathrm{O}}\right)$ and to achieve p-type doping [3, 7, 10, 13-17]. Li et al. [10] found that p-doping is gotten with post-annealing at 615 ${ }^{\circ} \mathrm{C}$ during 25 minutes on Ag-N doped $\mathrm{ZnO}$ films. With the Al-N codoping system: Liu et al. [13] developed p-type films with post-annealing during $30 \mathrm{~min}$ at temperatures between 575 and $600{ }^{\circ} \mathrm{C}$. Kumar et al. [14] observed p-type at temperatures higher that $400{ }^{\circ} \mathrm{C}$, they remark that $600{ }^{\circ} \mathrm{C}$ is the best. Yang et al. [16] studied sol-gel codoped $\mathrm{ZnO}$ films and they found optimized p-type conduction at $550{ }^{\circ} \mathrm{C}$.

In this paper, we study the influence of annealing temperature on the structural properties of Al- $\mathrm{N}$ codoped $\mathrm{ZnO}$ films grown on $\mathrm{Si}(100)$ at $20{ }^{\circ} \mathrm{C}$ by X-ray diffraction, photoluminescence and Raman microscopy in order to get a best understanding of both the intrinsic defects and NO density behavior during the annealing process.

\section{MATERIALS AND METHODS}

Al-N codoped $\mathrm{ZnO}$ films were deposited on silicon (100) substrates by sputtering technique. All Si substrates were ultrasonically cleaned sequentially in acetone, methanol, and then deionized water. All samples were grown using a co-sputtering technique of dual targets: a ceramic $\mathrm{ZnO}$ target at $\mathrm{RF}$ power of $150 \mathrm{~W}$ and a pure $\mathrm{Al}$ (purity 99.9\%) at DC power of $50 \mathrm{~W}$. During the film deposition substrate temperature and deposition time were kept constant at $20^{\circ} \mathrm{C}$ and $17 \mathrm{~min}$, respectively. High purity argon $(99.999 \%)$ and nitrogen $(99.999 \%)$ were used as sputtering gases, the flow rate of argon was fixed at $6 \mathrm{sccm}$, whereas the flow rate of nitrogen was varied at 6,12 and $15 \mathrm{sccm}$. The Al-N codoped $\mathrm{ZnO}$ films were annealed in air for 30 minutes at temperatures of $300,400,500,600$ and $700{ }^{\circ} \mathrm{C}$. The crystallinity of the samples was characterized using X-ray diffraction (XRD, Bruker D8 Advance). Room temperature photoluminescence (PL) was carried out using a He-Cd laser with excitation wavelength 325 and power of $16 \mathrm{~mW}$. Raman microscopy study was performed with a $532 \mathrm{~nm}$ laser line of $10 \mathrm{~mW}$ as excitation source (DXR model, Thermo Scientific).

\section{RESULTS AND DISCUSSION}

\subsection{Before annealing}

Figure 1 shows XRD patterns of $\mathrm{ZnO}$ films before thermal treatment for nitrogen flow rate of 6 (N6), 12 (N12) and $15 \mathrm{sccm}(\mathrm{N} 15)$. The patterns have a slow mismatch with the reference positions of undoped $\mathrm{ZnO}$ films due to the stress originated by the incorporation of both $\mathrm{Al}$ and $\mathrm{N}$ atoms. In sample N6, seven diffraction peaks corresponding to the (100), (002) (101) (102), (110), (103) and (112) planes are observed, the first three with major intensity. For samples N12 and N15, ZnO films exhibit (002) preferential orientation with the c-axis perpendicular to the substrate. As increase of $\mathrm{N}$ content, the full width at half maximum (FWHM) of the (002) peak decreases clearly, indicating the improving crystallinity due to incorporation of $\mathrm{N}$ atoms. 


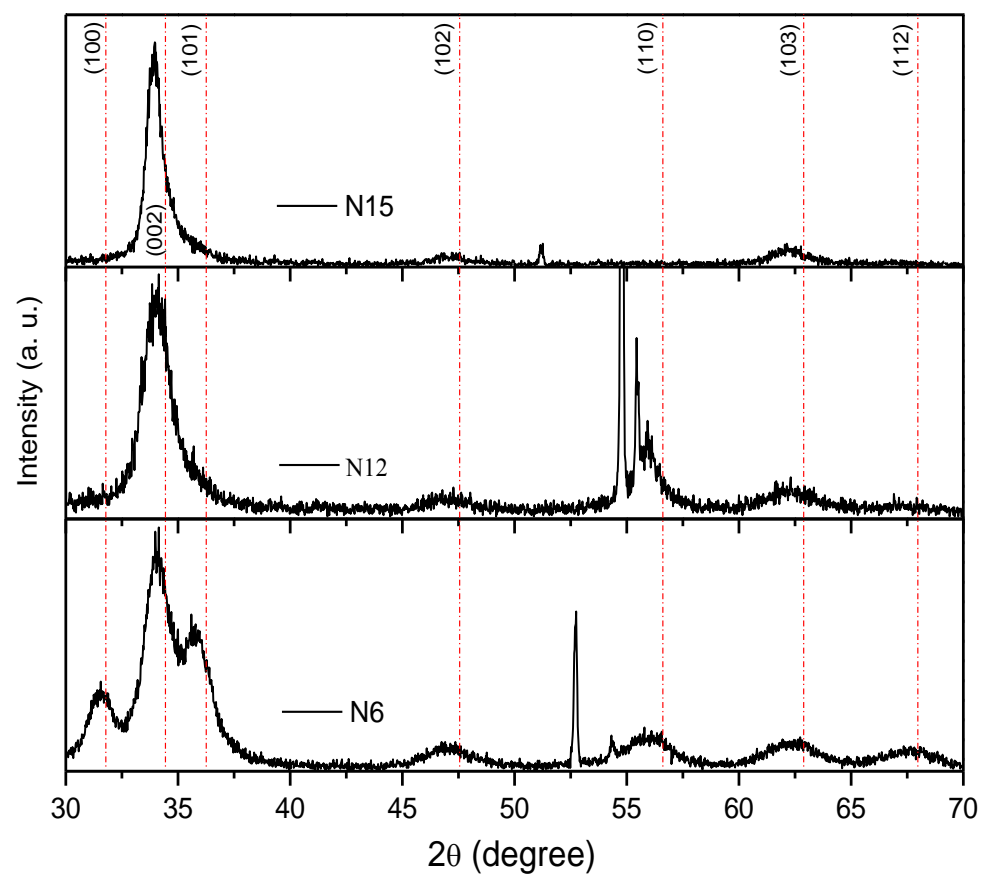

Figure 1. XRD patterns of $\mathrm{ZnO}$ films as-groth with flow rate nitrogen of 6 (N6), 12 (N12) and $15 \mathrm{sccm}$ (N15) before thermal treatment. Red lines indicate location peak for undoped $\mathrm{ZnO}$ films.

Figure 2 shows PL spectra of samples N6, N12 and N15, where is evident a broad band between 1.7 and $3.1 \mathrm{eV}$ that could be originated by interstitial defects $\left(\mathrm{Zn}_{\mathrm{i}}, \mathrm{O}_{\mathrm{i}}, \mathrm{N}_{\mathrm{i}}\right.$ and $\left.\mathrm{Al}_{\mathrm{i}}\right)$. We cannot see the band to band transition near to $3.36 \mathrm{eV}$, suggesting a poor crystal quality. On samples where the $\mathrm{N}$ content increase (N12 and N15), the signal associated to interstitial defects is diminished, the bandgap transition is possible to see clearly and the signal associated to oxygen vacancies $(1.62 \mathrm{eV})$ is observable too.

In order to estimate the nitrogen incorporation to the oxygen sites $\left(\mathrm{N}_{\mathrm{O}}\right)$, Raman measurements were made. Figure 3 displays the Raman spectra of N6, N12 and N15 samples, where we can see two vibration modes located at 275 and $580 \mathrm{~cm}^{-1}$ originated by the Al-N codoped $\mathrm{ZnO}$ films and two more by the $\mathrm{Si}$ substrate. There is an old controversy about the accurate origin of 275 Raman mode, but it has been frequently related to the NO concentration and to the presence of point defects $\left(\mathrm{Zn}_{\mathrm{i}}\right.$ specifically) [20-24]. Raman intensities of both modes, I275 and I580, decreases when the nitrogen flow increases from 6 to 12 and $15 \mathrm{sccm}$. Other authors suggesting that the increase of nitrogen flow mitigates the formation of interstitial defects [23]. In this work, we can see good agreement between XRD, PL and Raman measurements: the interstitial defects decrease as the $\mathrm{N}$ flow increase in samples grown at $20^{\circ} \mathrm{C}$.

\subsection{After annealing}

Figure 4 shows the XRD patterns of sample growth with $12 \mathrm{sccm}$ nitrogen flow after the annealing process at temperatures between 300 and $700{ }^{\circ} \mathrm{C}$. As we can see, the (002) peak shifts to high angles (residual stress decrease) and the FWHM decrease as the temperature increase. Patterns of N6 and N15 samples presented similar behavior (not showed here). The XRD patterns behavior is clear evidence that the crystal quality has improved after annealing treatment, this suggests that interstitial defects concentration decreases as the temperature increase.

Figure 5 shows the Raman spectrum of N12 samples after annealing, where we can see that both $\mathrm{I} 275$ and I580 modes increases as the temperature increases, reaches a maximum around $500{ }^{\circ} \mathrm{C}$ and decreases at higher temperatures. Considering that interstitial defects are decreasing, the 1275 behavior is generated mostly by the $\mathrm{N}_{O}$ concentration. At high temperatures, this signal is diminishing because more. oxygen vacancies are generated, which play like n-type doping. The Raman behavior is in good agreement with other reports where has reported that optimal temperature is between 500 and $600{ }^{\circ} \mathrm{C}[13,16]$. 


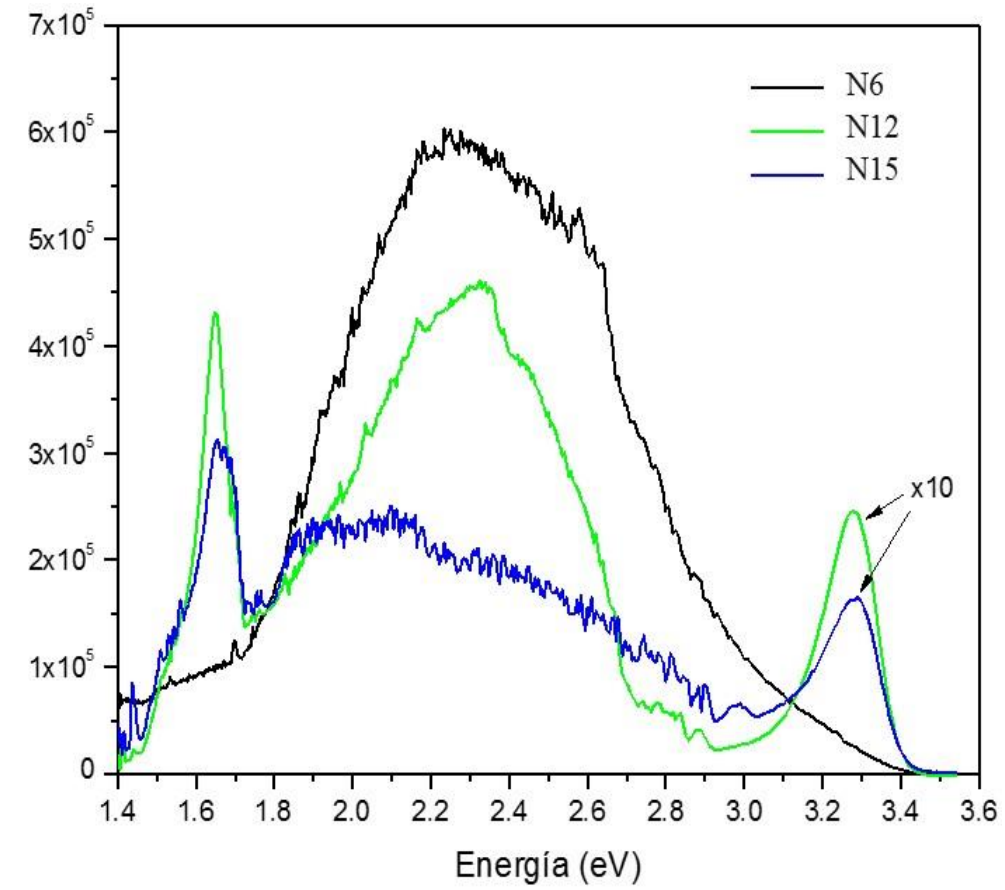

Figure 2: Room temperature photoluminescence of $\mathrm{Al}-\mathrm{N}$ codoped $\mathrm{ZnO}$ with 6, 12 and $15 \mathrm{sccm}$ nitrogen flow. The N12 and N15 spectra were magnified by 10 .

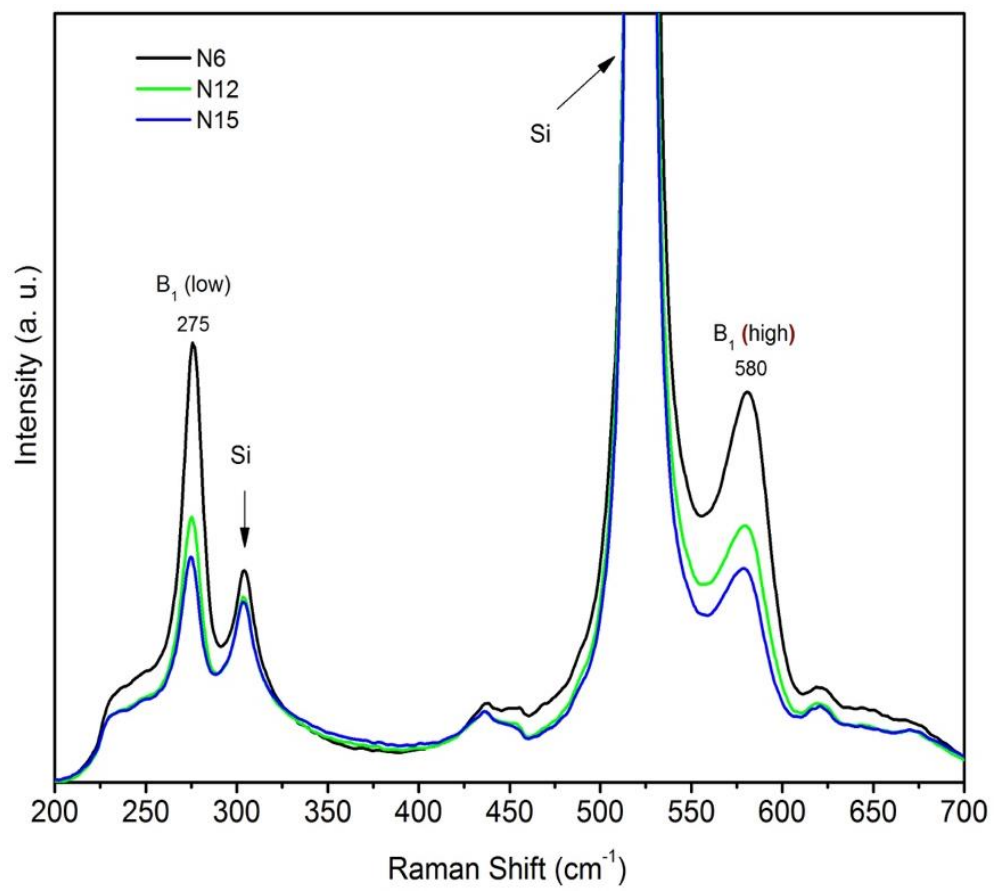

Figure 3: Raman spectra of ZnO films codoped with 6 (N7), 12 (N12) and $15 \mathrm{sccm}$ (N15) nitrogen flow. 


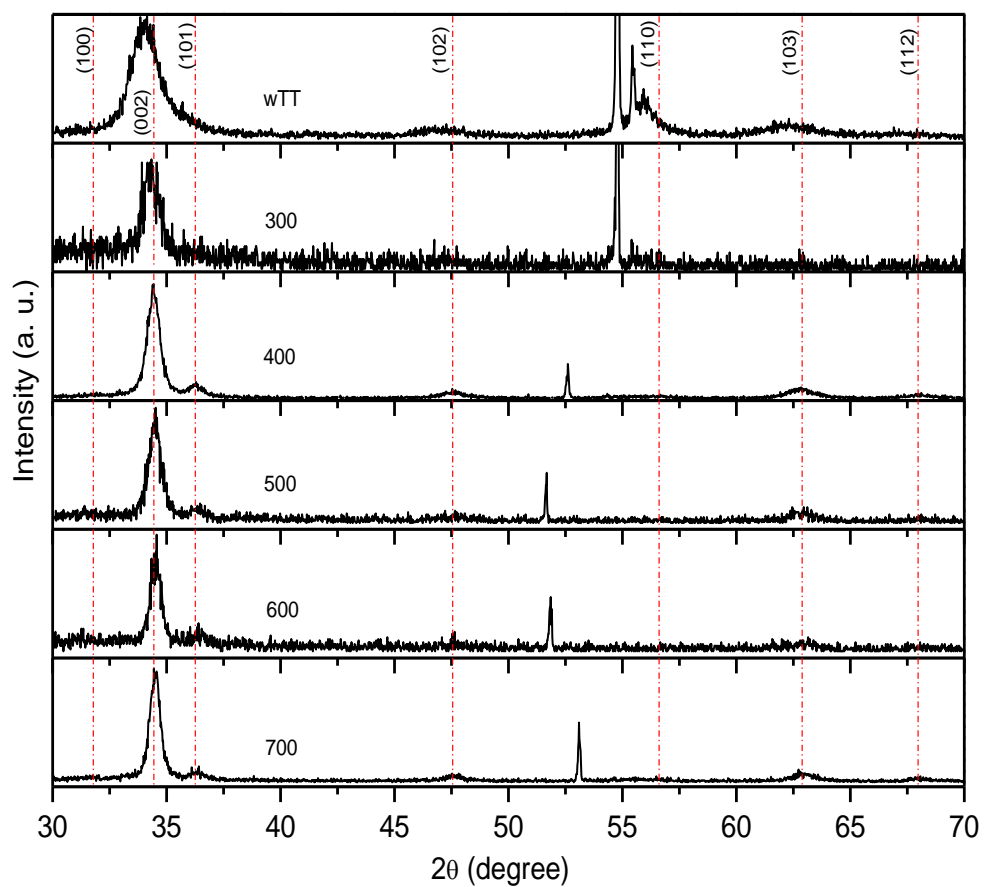

Figure 4: XRD patterns of N12 after thermal treatment compared wit the spectra without thermal treatment (wTT).

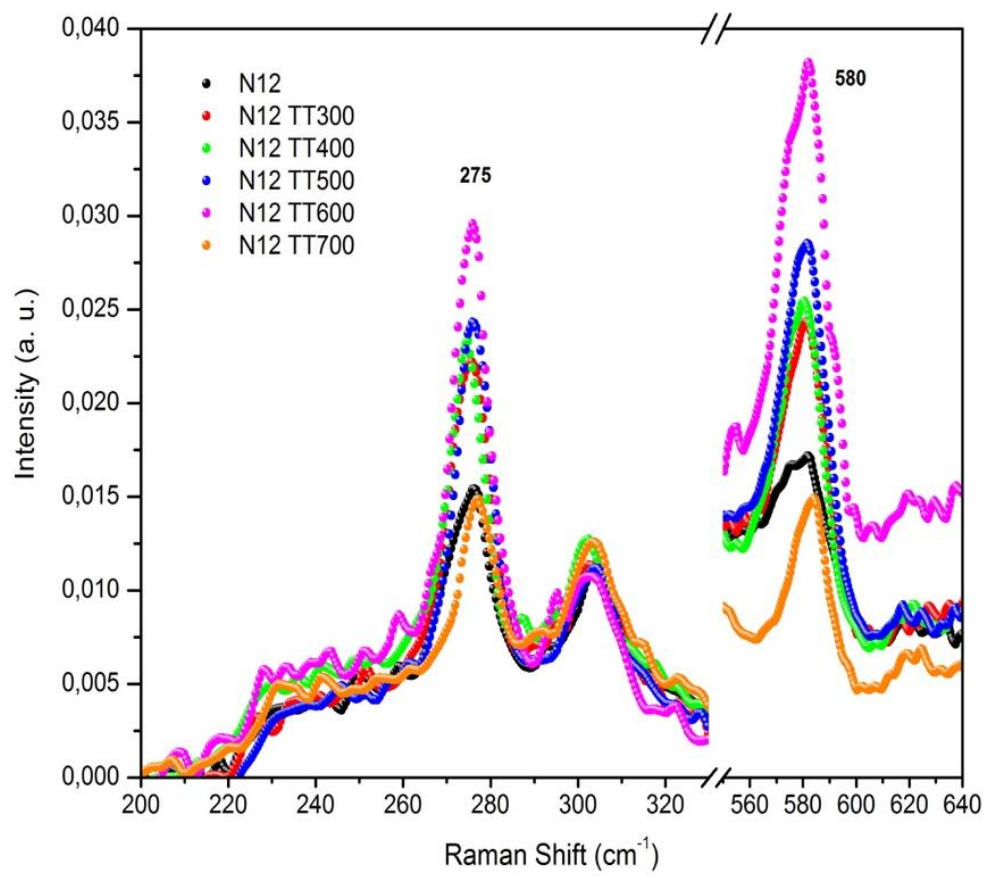

Figure 5: Raman spectra of N12 sample after thermal treatment at different temperatures, compared with the spectrum without treatment.

\section{CONCLUSIONS}

In this work, the effect of annealing temperature on the structural properties of Al-N codoped $\mathrm{ZnO}$ films have been studied. When the nitrogen content was increased a better crystal quality was observed by XRD, photoluminescence and Raman measurements, originated by the diminishing of the interstitial defects concentration. After annealing, in the Raman spectra it was observed that the Raman mode associated to the complex $\mathrm{Zn}_{\mathrm{i}}-\mathrm{N}_{\mathrm{O}}$ (I275) increases as the temperature increase, reached a maximum intensity between 500 and $600{ }^{\circ} \mathrm{C}$, and decreased for higher temperatures. X-ray diffraction measurements showed that after annealing the compressive stress decrease progressively as the temperature annealing increase. This study suggests that 275 
Raman mode could be used to estimate the optimal annealing temperature in order to achieve p-doping $\mathrm{ZnO}$ films.

\section{ACKNOWLEDGMENTS}

We acknowledge the financial supports of SEP Mexico, through to the PRODEP project "Red Temática Nanomateriales".

\section{BIBLIOGRAPHY}

[1] KOHAN, F., CEDER, G., MORGAN, D., et al., "First-principles study of native point defects in ZnO", Physical Review B, v. 61, n. 22, pp. 15019-15027, jun. 2000.

[2] SAW, K. G., IBRAHIM, K., LIM, Y.T., "Self-compensation in ZnO thin films: An insight from X-ray photoelectron spectroscopy, Raman spectroscopy and time-of-flight secondary ion mass spectroscopy analyses", Thin Solid Films, v. 515, pp. 2879-2884, 2007.

[3] ZHANG, H., KONG, C., LI, W., et al., "The formation mechanism and stability of p-type N-doped Znrich ZnO films", J Mater Sci: Mater Electron, v. 27, pp. 5251-5258, 2016.

[4] YAMAMOTO, T., KATAYAMA-YOSHIDA, H. "Physics and control of valence states in $\mathrm{ZnO}$ by codoping method", Physica B, v. 302-303, 155-162, 2001.

[5] VAITHIANATHAN, V., PARK, J. Y., KIM, S. S. "Electrical Properties of Sputtered ZnO Films with Nitrogen and Phosphorous Co-doping”, Metals and Materials International, v. 14, pp. 471-475, 2008.

[6] TIAN, R.-Y., ZHAO, Y.-J. "The origin of p-type conduction in (P, N) codoped ZnO", J. Appl. Phys., v.106, 2009.

[7] KONG, J. F., YE, H. B., ZHANG, D. M., et al., "Temperature-dependent Raman scattering in N-In codoped p-type ZnO thin films”, J. Phys. D: Appl. Phys., v. 40, pp. 7471-7474, 2007.

[8] CHEN, L. L., LU, J. G., YE, Z. Z., et al., "p-type behavior in In-N codoped ZnO thin films", Applied Physics Letters, v. 87, 2005.

[9] CHEN, M., ZHU, Y., JI, X., et al., "The role of Be incorporation in the modulation of the N doping ZnO”, Journal of Alloys and Compounds, v. 622, pp. 719-724, 2015.

[10] Li, W., Kong, C., Qin, G., et al., "p-Type conductivity and stability of Ag-N codoped ZnO thin films", Journal of Alloys and Compounds, v. 609, pp. 173-177, 2014.

[11] ZENG, Y. J., YE, Z.-Z.,. LU, J. G., et al., "Effects of Al content on properties of Al-N codoped ZnO films”, Applied Surface Science, v. 249, 203-207, 2005.

[12] Cho, S. "Properties of nitrogen and aluminium-codoped $\mathrm{ZnO}$ thin films grown with different nitrogen flow ratios for solar cell applications", Current Applied Physics, v. 10, pp. S443-S446, 2010.

[13] LIU, Z. W., YEO, S.W., ONG, C.K. "Achieve p-type conduction in N-doped and (Al,N)-codoped ZnO thin films by oxidative annealing zinc nitride precursors”, J. Mater. Res., v. 22, pp. 2668-2675, 2007.

[14] KUMAR, M., KIM, S. K., CHOI, S. Y. "Formation of Al-N co-doped p-ZnO/n-Si (1 000$)$ heterojunction structure by RF co-sputtering technique”, Applied Surface Science, v. 256, pp. 1329-1332, 2009.

[15] LIU, Y. Y., JIN, H. J., PARK, C. B., "PL Property of Al-N Codoped p-type ZnO Thin Films Fabricated by DC Magnetron Sputtering”, Trans. Electr. Electron. Mater., v. 10, n.3, pp. 89, 2009.

[16] YANG, T.-H., WU, J.-M. "Thermal stability of sol-gel p-type Al-N codoped ZnO films and electric properties of nanostructured $\mathrm{ZnO}$ homojunctions fabricated by spin-coating them on $\mathrm{ZnO}$ nanorods", Acta Materialia 60 (2012) 3310-3320.

[17] KALYANARAMAN, S., THANGAVEL, R., VETTUMPERUMAL, R. "High mobility formation of ptype Al doped ZnO:N films annealed under NH3 ambient", Journal of Physics and Chemistry of Solids, v. 74, pp. 504-508, 2013.

[18] TUZEMEN, E. S., KARA, K., TAKCI, D. K. "Comparison of N-doped ZnO and N-Al codoped ZnO thin films deposited by pulsed filtered cathodic vacuum arc deposition”, Indian J. Phys, v. 89, pp. 337, 2015.

[19] PATHAK, T. K., KUMAR, V., PUROHIT, L. P. "Sputtered Al-N codoped p-type transparent ZnO thin films suitable for optoelectronic devices”, Optik, v. 127, pp. 603-607, 2016.

[20] MANJÓN, F. J., MARÍ, B., SERRANO, J., et al., "Silent Raman modes in zinc oxide and related nitrides", J. Appl. Phys., v. 97, 2005. 
[21] YU, J., XING, H., ZHAO, O., et al., "The origin of additional modes in Raman spectra of NC-implanted ZnO”, Solid State Communications, v. 138, pp. 502-504, 2006.

[22] FRIEDRICH, F., GLUBA, M. A., NICKEL, N. H. "Identification of nitrogen and zinc related vibrational modes in ZnO", Appl. Phys. Lett. v. 95, 2009.

[23] WU, K., FANG, Q., WANG, W., et al., "On the origin of an additional Raman mode at $275 \mathrm{~cm}-1$ in Ndoped ZnO thin films", J. Appl. Phys. v. 111, 2012.

[24] ZHANG, P., KONG, C., LI, W., et al., "The origin of the $\sim 274 \mathrm{~cm}-1$ additional Raman mode induced by the incorporation of $\mathrm{N}$ dopants and a feasible route to achieve p-type $\mathrm{ZnO}: \mathrm{N}$ thin films", Applied Surface Science, v. 327, pp. 154-158, 2015. 